Diabetologia (1995) 38: 983-985

\title{
A mutation in the glucagon receptor gene (Gly40Ser): heterogeneity in the association with diabetes mellitus
}

\author{
T. Fujisawa ${ }^{1}$, H. Ikegami ${ }^{1}$, E. Yamato ${ }^{1}$, K. Takekawa ${ }^{1}$, Y. Nakagawa ${ }^{1}$, Y.Hamada ${ }^{1}$, H. Ueda ${ }^{1}$, M. Fukuda ${ }^{2}$, \\ T. Ogihara ${ }^{1}$ \\ ${ }^{1}$ Department of Geriatric Medicine, Osaka University Medical School, Osaka, Japan \\ ${ }^{2}$ Department of Ophthalmology, Osaka Teishin Hospital, Osaka, Japan
}

\begin{abstract}
Summary A possible pathogenic mutation in the glucagon receptor gene causing a Gly to Ser change at codon 40 (Gly40Ser) was reported to be associated and linked with non-insulin-dependent diabetes mellitus (NIDDM), in France and Sardinia. Since the frequency of the mutation (Gly40Ser), about $5 \%$ in the French population of familial NIDDM and $8 \%$ in randomly chosen diabetic patients in Sardinia, was much higher than that of any of the previously reported mutations in candidate genes, it is important to clarify whether the contribution of this mutation to NIDDM is universal. In this study, we investigated the association of this mutation with diabetes mellitus in a large number of Japanese diabetic patients (383 NIDDM and 53 insulin-dependent diabetic patients) by polymerase chain reaction-restriction frag-
\end{abstract}

ment length polymorphism analysis. None of the Japanese diabetic patients showed Gly40Ser mutation and the association of this mutation with NIDDM was significantly different $\left(p<4 \cdot 10^{-5}\right.$ vs French, $p<3 \cdot 10^{-6}$ vs Sardinian by Fisher's exact test). The results not only indicate that the mutation plays little, if any, role in susceptibility to diabetes in Japan, but also indicate the genetic heterogeneity in NIDDM and further emphasize the importance of studies on genetic susceptibility to NIDDM and other complex traits in different ethnic groups. [Diabetologia (1995) 38: 983-985]

Key words Glucagon receptor gene, susceptibility, missense mutation, non-insulin-dependent diabetes mellitus.
Non-insulin-dependent diabetes mellitus (NIDDM) is a genetically heterogeneous disorder, and several mutations in the candidate genes have been identified. However, these mutations are present in only a few diabetic patients. Recently, Hager et al. [1] reported an association and linkage between NIDDM and a possible pathogenetic mutation in the glucagon receptor gene causing a Gly to Ser change at codon 40 (Gly40Ser), in France and Sardinia. The frequency of the mutation (Gly40Ser), about $5 \%$ in the

Received: 27 April 1995

Corresponding author: Dr. H. Ikegami, Department of Geriatric Medicine, Osaka University Medical School, 2-2 Yamadaoka, Suita, Osaka 565, Japan

Abbreviations: NIDDM, Non-insulin-dependent diabetes mellitus; PCR, polymerase chain reaction; RFLP, restriction fragment length polymorphism; IDDM, insulin-dependent diabetes mellitus.
French population of familial NIDDM and $8 \%$ in randomly chosen diabetic patients from Sardinia, was significantly higher than that in control subjects. Since the frequency of the mutation was much higher than that of any of the previously reported mutations in candidate genes, such as glucokinase [2-4], mitochondria $[5,6]$, insulin and insulin receptor genes, it is important to clarify whether the contribution of this mutation to NIDDM is universal.

In this study, we investigated the association of this mutation with diabetes in Japanese patients by polymerase chain reaction-restriction fragment length polymorphism analysis (PCR-RFLP).

\section{Subjects and methods}

We investigated 383 unrelated Japanese patients with NIDDM, diagnosed according to the guidelines of the $\mathrm{Na}$ tional Diabetes Data Group. Of these patients $228(60 \%)$ had 
Table 1. Frequencies of a Gly40Ser mutation in the glucagon receptor gene in diabetes mellitus

\begin{tabular}{llll}
\hline Population & Diabetes type & Gly40Ser mutation & $(\%)$ \\
\hline French $^{\mathrm{a}}$ & NIDDM & $10 / 216$ & $(4.6)$ \\
Sardinian $^{\mathrm{a}}$ & NIDDM & $8 / 96$ & $(8.3)$ \\
Japanese $^{\mathrm{b}}$ & NIDDM & $0 / 383$ & $(0.0)^{\mathrm{c}, \mathrm{d}}$ \\
& IDDM & $0 / 53$ & $(0.0)$ \\
\hline
\end{tabular}

Data from [1]

b This study

${ }^{c} p<4 \cdot 10^{-5}$ vs French NIDDM (Fisher's exact test)

${ }^{d} p<3 \cdot 10^{-6}$ vs Sardinian NIDDM (Fisher's exact test)

a family history of diabetes in their first-degree relatives. Fiftythree patients with insulin-dependent diabetes mellitus (IDDM) were also investigated. DNA, extracted from peripheral blood leukocytes, was used for the detection of the Gly40Ser mutation by PCR-RFLP analysis as reported [1] and the PCR products were separated on $9 \%$ polyacrylamide gel.

\section{Statistical analysis}

Data are expressed as mean \pm SD and the significance of the difference in mutation frequencies was determined by Fisher's exact test.

\section{Results}

Patients with NIDDM were $15-86$ years of age with an age at diagnosis $45.7 \pm 12.3$ years. Patients with IDDM were 13-76 years of age with an age at onset $25.9 \pm 13.7$ years.

In our study, all the 436 subjects tested were homozygote for wild-type allele, indicating that the mutation in the glucagon receptor gene (Gly40Ser) was not found in any Japanese subjects. Compared with the previous report [1], the association of Gly40Ser mutation with NIDDM was significantly different (Table 1).

\section{Discussion}

None of the Japanese diabetic patients in this study had the mutation in the glucagon receptor gene (Gly40Ser). The association of Gly40Ser mutation with NIDDM in Japanese subjects was significantly different (Table 1) compared with that of French and Sardinian populations, suggesting that the contribution of this gene to NIDDM may not be universal or merely that a founder effect was not observed in our isolated population.

The reason for the different frequencies between the two studies is not clear, but one possible reason is racial difference; i.e., difference in genetic and environmental background which might lead to devel- opment of NIDDM. In fact, racial differences in the association of candidate genes with NIDDM have previously been reported. Association of the glucokinase gene polymorphism with diabetes was observed in American black [2] and Japanese [3,4], but not Caucasoid subjects [7]. Similarly, the glycogen synthase gene polymorphism was associated with NIDDM in Finnish [8] and French [9], but not in Japanese subjects [10]. Different frequencies of the 3243 mutation in mitochondrial DNA among different ethnic groups have also been reported $[5,6]$. Given the likely heterogeneity of NIDDM, the importance of the glucagon receptor gene in susceptibility to NIDDM may also vary in different ethnic groups.

Our data showing that the glucagon receptor gene polymorphism (Gly40Ser) was not found in Japanese individuals does not necessarily indicate that this gene does not contribute to genetic susceptibility to NIDDM in Japanese patients, because the five other reported polymorphisms in the gene were not investigated in our study. However, the high frequency (5$8 \%$ ) of the Gly40Ser mutation in NIDDM observed in France and Sardinia [1] was not confirmed in Japanese subjects, suggesting that the contribution of this mutation to the pathogenesis of NIDDM may not be universal. The results indicate the genetic heterogeneity in NIDDM and further emphasize the importance of studies on genetic susceptibility to NIDDM and other complex traits in different ethnic groups.

In conclusion, the absence of the Gly40Ser mutation in 383 Japanese patients with NIDDM and 53 patients with IDDM makes it unlikely that this mutation is the major cause of genetic susceptibility to diabetes in Japanese subjects. The role of glucagon receptor in diabetes in other ethnic groups remains to be explored.

Acknowledgements. We thank Ms. Y. Ueno for her skilful technical support. This work was supported in part by a Grant for Diabetes Research from the Ministry of Health and Welfare, a Grant-in-Aid for Scientific Research from the Ministry of Education, Science and Culture of Japan and a Grant from the Japan Diabetes Foundation.

\section{References}

1. Hager J, Hansen L, Vaisse C et al. (1995) A missense mutation in the glucagon receptor gene is associated with noninsulin-dependent diabetes mellitus. Nature Genetics 9: 299-304

2. Chiu KC, Province MA, Permutt MA (1992) Glucokinase gene is a genetic marker for NIDDM in American blacks. Diabetes 41: 843-849

3. Noda K, Matsutani A, Tanizawa Y et al. (1993) Polymorphic microsatellite repeat markers at the glucokinase gene locus are positively associated with NIDDM in Japanese. Diabetes 42: 1147-1152

4. Takekawa K, Ikegami H, Fukuda M et al. (1994) Early-onset type 2 (non-insulin-dependent) diabetes mellitus is associated with glucokinase locus, but not with adenosine 
deaminase locus, in the Japanese population. Diabetes Res Clin Pract 23: 141-146

5. Kadowaki T, Kadowaki H, Mori Y et al. (1994) A subtype of diabetes mellitus associated with a mutation of mitochondrial DNA. N Engl J Med 330: 962-968

6. 't Hart LM, Lemkes HHPJ, Heine RJ et al. (1994) Prevalence of maternally inherited diabetes and deafness in diabetic populations in the Netherlands. Diabetologia 37: 1169-1170

7. Permutt MA, Chiu KC, Yukio T (1992) Glucokinase and NIDDM: a candidate gene that paid off. Diabetes 41 : 1367-1372
8. Groop LC, Kankuri M, Schalin-Jäntti C et al. (1993) Association between polymorphism of the glycogen synthase gene and non-insulin-dependent diabetes mellitus. N Engl J Med 328: 10-14

9. Zouali H, Velho G, Froguel P (1993) Polymorphism of the glycogen synthase gene and non-insulin-dependent diabetes mellitus. N Eng1 J Med 328: 1568

10. Kadowaki T, Kadowaki H, Yazaki Y (1993) Polymorphism of the glycogen synthase gene and non-insulin-dependent diabetes mellitus. N Engl J Med 328: 1568-1569 